\title{
Expanding the snow-climate classification with avalanche-relevant information: initial description of avalanche winter regimes for southwestern Canada
}

\author{
Pascal HAEGELI, ${ }^{1 *}$ David M. MCCLUNG ${ }^{2}$ \\ ${ }^{1}$ Atmospheric Science Program, University of British Columbia, 1984 West Mall, Vancouver, British Columbia V6T 1Z2, \\ Canada \\ E-mail: pascal@avisualanche.ca \\ ${ }^{2}$ Department of Geography, University of British Columbia, 1984 West Mall, Vancouver, British Columbia V6T 1Z2, Canada
}

\begin{abstract}
Existing snow-climate classifications are primarily based on meteorological parameters that describe the average weather during the main winter months. However, field experience and measurements show that the characteristics of weak snowpack layers, including type, structure and details of formation, are primary indicators of avalanches that form. Despite its importance in the characteristics of local avalanche activity, weak-layer information is currently not a formal part of any snow-climate classification scheme. The focus of this study is the analysis of persistent snowpack weak layers in southwestern Canada. Observations from the industrial information exchange (InfoEx) of the Canadian Avalanche Association are used to examine the frequency, sequence and distribution of the most common types of snowpack weakness and their related avalanche activity. The results show significant temporal and spatial variations in areas with the same snow-climate characteristics. The weak-layer patterns observed in transitional snow-climate areas are clearly more complex than a simple combination of maritime and continental influences. 'Avalanche winter regime' is suggested as a new classification term that describes the snowpack structures relevant for local avalanche activity and complements the existing snow-climate classification system. Three preliminary avalanche winter regimes are identified for southwestern Canada.
\end{abstract}

\section{INTRODUCTION}

Climate classifications have been used for a long time to divide the Earth's atmosphere-hydrosphere-cryosphere system into regions that are homogeneous with respect to specific climatic elements. Different classifications provide problem-specific reference systems that are typically described by a small number of suitable averages or ranges of relevant parameters. One of the most popular climate classifications is Köppen (1918), which is based on annual and seasonal temperature and precipitation values. Although proper classifications can considerably improve our understanding and modeling capabilities of specific phenomena, it is important to remember the limitations of the original classification definitions.

The three types of snow climate, namely maritime, continental and transitional (Roch, 1949; LaChapelle, 1966; McClung and Schaerer, 1993), are well established and have been used in many snow and avalanche studies to describe the general snow and avalanche characteristics of the study area (e.g. Mingo and McClung, 1998; Birkeland, 2001). While the maritime and continental snow climates represent the two main types, the transitional type exhibits intermediate characteristics. A detailed historical review of the development and usage of these terms in North America is given in Hägeli and McClung (2003). Existing snowclimate classifications are primarily based on meteorological parameters. The most recent classification method by

*Present address: School for Resource and Environmental Management, Simon Fraser University, 8888 University Drive, Burnaby, British Columbia V5A 1S6, Canada.
Mock and Birkeland (2000), for example, focuses on the average weather during the main winter months (December-March) and uses mean air temperature, total rainfall, total snowfall, total snow water equivalent (SWE) and a derived average December snowpack temperature gradient to classify the local snow climate.

Field experience and measurements show that the primary indicator of avalanche formation is the stratigraphy of the snowpack, including the detailed slab and weak-layer properties (Schweizer and others, 2003). While directaction avalanches (McClung, 2002) form during single storm cycles, avalanches related to persistent weak layers (Jamieson, 1995), also known as climax avalanches (McClung, 2002), are the result of specific sequences of weather events. Since current snow-climate definitions do not formally include any weak-layer information, they can only provide limited insights into the characteristics of local avalanche activity.

As pointed out by LaChapelle (1966), direct-action avalanches can be forecasted reliably based on current meteorological evidence. The forecasting of climax avalanches is a bigger challenge as it requires an integration of the entire weather history of a season. Snowpack structure observations, including detailed information about slab and weak-layer properties, are crucial for predicting this type of avalanche. In order to provide useful background information for the development of avalanche safety programs, a comprehensive avalanche climate definition should include basic information about the distribution and frequency of the important local persistent weak layers.

The goal of this study is to extend existing snow-climate classifications with information about the characteristics of 


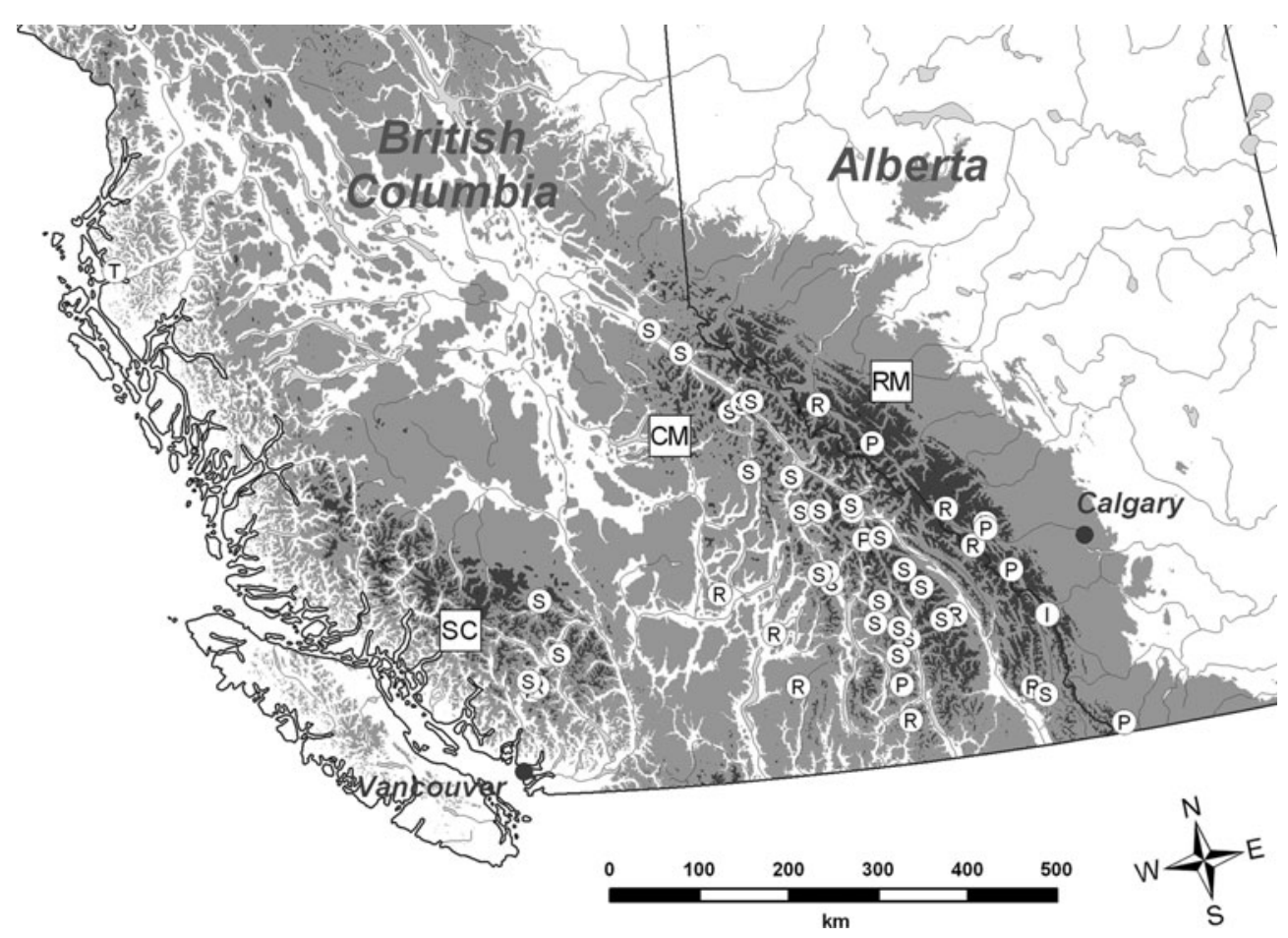

Fig. 1. Main mountain ranges in western Canada with InfoEx data coverage (SC: Southern Coast Mountains; CM: Columbia Mountains; RM: Rocky Mountains) and locations of operations reporting to InfoEx (I: mine or logging operation; P: park; R: ski resort; S: commercial mechanized and non-mechanized back-country ski operation).

persistent snowpack instabilities to allow a more comprehensive understanding of dominant avalanche activity patterns in southwestern Canada.

\section{STUDY AREA AND DATASET}

Southwestern Canada is an ideal area for a study on avalanche climate, as the three main mountain ranges, namely the Coast Mountains, the Columbia Mountains and the Rocky Mountains (Fig. 1), cover a wide variety of different snow and avalanche conditions (McClung and Schaerer, 1993).

Since the winter of 1991/92, the Canadian Avalanche Association (CAA) has been managing the industrial information exchange (InfoEx) among avalanche safety operations in southwestern Canada. The exchange generally runs from mid-November to the end of April, with the most consistent data stream occurring from the beginning of January to the end of March. On a peak day, approximately 55 operations submit weather and snow data from study plots and field observations; information about observed avalanche activity; comments about the current snowpack structure; and stability ratings. While weather and avalanche data are organized in tables (avalanche data only since season 2000/01), much of the important information is presented in semi-structured sometimes anecdotal comments. Gruber and others (2004) developed a parsing code to extract the information from the archived text files and transfer it into an accessible database format. The resulting database includes approximately 45000 avalanche records, 43000 weather observations and 41000 comments regarding snowpack structure and stability ratings. The average daily observation area is estimated at approximately $40000 \mathrm{~km}^{2}$ and includes observations from all three snow climates, making the InfoEx database one of the most comprehensive back-country avalanche datasets currently available (Gruber and others, 2004).

The data contained in the InfoEx dataset are strongly influenced by the distribution and type of submitting operations. Different regions of the study area are dominated by different combinations of types of contributing operation (Fig. 1), which can introduce various observational biases to the data. Operational avalanche datasets are also inherently incomplete and skewed. Avalanche information is incomplete due to observational difficulties, such as large operation areas or poor visibility (Laternser and Schneebeli, 2002; Hägeli and McClung, 2003), and snowpack observations may be skewed by the practice of targeted sampling (McClung, 2002). While scientific datasets are commonly based on random or systematic sampling techniques, avalanche professionals specifically seek information about snow instability. A more comprehensive description of the InfoEx dataset and its limitations can be found in Hägeli (2004).

The inherent incompleteness of large-scale avalanche observations fundamentally prevents the development of spatially distributed avalanche climate definitions that are based on avalanche activity statistics, such as the long-term percentage of avalanche activity on persistent weak layers. However, an analysis of avalanche and snowpack observations related to persistent weak layers can still provide significant insights about the characteristics of local avalanche activity. From this perspective, the operational focus of the InfoEx dataset is an important advantage for this study.

The analysis of persistent weak layers discussed in this paper focuses on observations from the winter seasons 1996/ 97 to 2001/02. Starting in 1996/97, the reporting of persistent weak-layer information in the InfoEx dataset became more frequent and the data quality became reasonably consistent during this time period. The CAA is currently in the process of redesigning its data systems, and the InfoEx 


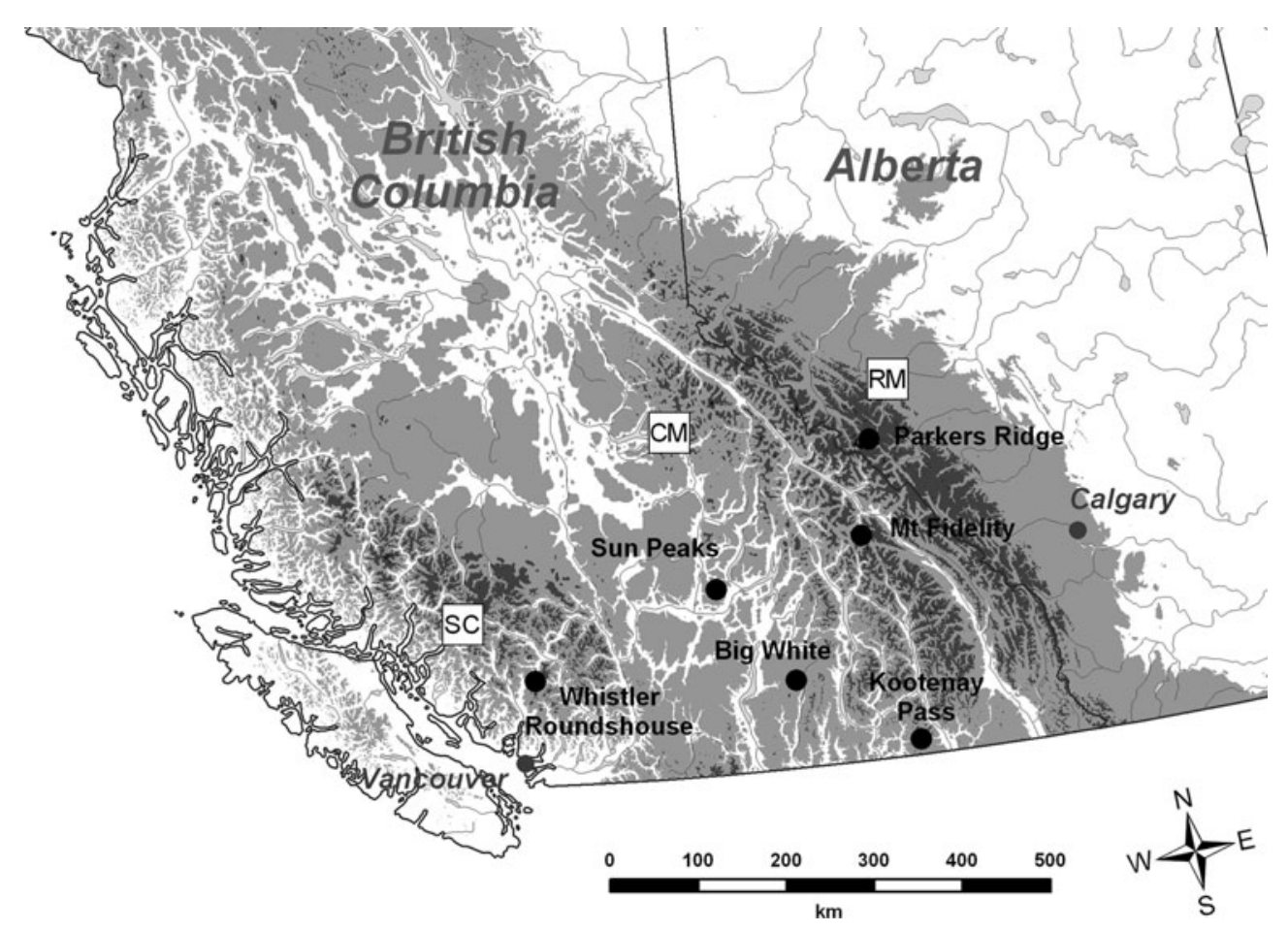

Fig. 2. Locations of weather study plots used for the meteorological snow-climate analysis (black dots).

dataset from seasons since 2002 is presently in a format that does not allow its integration into the present analysis.

It is a common practice in the InfoEx dataset to label important persistent weak layers with their date of burial. This convention allows the tracking of these layers throughout a season. The exact labelling of individual weak layers was not always consistent among reporting operations, and burial dates often differed by 1 or 2 days (Gruber and others, 2004). However, with the help of weather records it was relatively easy to group the weak layers correctly.

Snow-climate studies require continuous meteorological data from high-elevation sites representative of starting zone conditions. Since the majority of InfoEx weather observations are taken at valley bottoms and generally cover only the time period of the peak winter months (Gruber and others, 2004), they were of limited use for this study. The Meteorological Service of Canada (MSC) maintains five high-elevation weather stations with reliable long-term records that allow a climatological analysis (Fig. 2). The locations are: Whistler Roundhouse (South Coast Mountains, 1835 ma.s.I.); Sun Peaks (Columbia Mountains, 1814 m a.s.I.); Glacier Park Mount Fidelity (Columbia Mountains, 1875 ma.s.l.); Big White (Columbia Mountains, 1841 ma.s.l.) and Parkers Ridge (Rocky Mountains, 2023 m a.s.I.). Since 1980, these stations have daily records of minimum, maximum and mean temperature, amounts of snowfall and precipitation, and height of snow on the ground. The dataset is complemented with weather information from the Kootenay Pass operation of the British Columbia Ministry of Transportation (Columbia Mountains, 1775 ma.s.l.). Numerous meteorological and nivological observations have been monitored there since 1981 .

\section{METHOD}

The present study builds heavily on the work of Hägeli and McClung (2003). While the previous study focused on the characterization of persistent weak layers in the transitional snow climate of the Columbia Mountains, the present study extends the analysis to the full range of snow climates in southwestern Canada.

The analysis was carried out in two steps. First, the snowclimate classification scheme of Mock and Birkeland (2000) was used to examine the main meteorological characteristics for the winters of 1980/81 to 2001/02. In a second step, InfoEx avalanche records and snowpack observations were examined to identify the distribution and frequency of relevant persistent snowpack weak layers (Jamieson, 1995) across the study area between 1996/97 and 2001/02.

\subsection{Snow-climate classification}

The classification scheme of Mock and Birkeland (2000) categorizes local winter conditions into one of the three traditional snow climates: maritime, transitional and continental (McClung and Schaerer, 1993). The scheme focuses on the main winter months (December-March) and uses the parameters of mean air temperature, total rainfall, total snowfall, total SWE and the derived average December snowpack temperature gradient for the classification (Fig. 3). The temperature gradient was calculated by dividing the difference of mean December air temperature and an assumed basal snowpack temperature of $0^{\circ} \mathrm{C}$ by the average December snow depth (Mock and Birkeland, 2000). The classification thresholds of the scheme are based on an analysis of meteorological data from 23 Westwide Avalanche Network sites in the western USA with at least 15 years of complete winter data. The sites were grouped according to the snow-climate discussion of Armstrong and Armstrong (1987), and threshold values were derived by analyzing box-plots of the different variables for the three different climates (Mock and Birkeland, 2000). In their study, Mock and Birkeland (2000) use the classification scheme to examine variations in spatial distribution of snow climates 
across the western USA as well as the temporal variations of winter characteristics at individual locations.

Meteorological data used in the first step of the present analysis did not have all of the necessary parameters for this classification scheme. The SWE values for MSC stations were estimated from daily snowfall records by assuming a seasonal average new snow density of $100 \mathrm{~kg} \mathrm{~m}^{-3}$ (see Röger, 2001). In the case of Kootenay Pass, daily rainfall was approximated by subtracting the SWE of new snow from values of total precipitation (Hägeli and McClung, 2003). Missing snow height measurements at Parkers Ridge were linearly interpolated between existing observation points. Whenever a station was missing a variable continuously for more than 10 days, its climate classification of the particular season was discarded from the analysis.

A baseline for the analysis of spatial and temporal variability of snow climates across the study area was established by applying the classification scheme of Mock and Birkeland (2000) to the climatological average values of the available weather records at the different weather stations. Subsequently, the classification scheme was applied to the records of individual winters to examine the distribution of snow-climate classifications in southwestern Canada in more detail.

\subsection{Analysis of persistent weak layers}

The goal of the second step of the analysis was to identify the frequency and spatial distribution of persistent weak layers (Jamieson, 1995) and their related avalanche activity across the study area. Because of the limitations in the dataset discussed earlier, it did not seem prudent to apply geostatistical methods, and, as a result, the present analysis is primarily qualitative in nature.

In this study, a persistent weak layer is defined as a snowpack layer that: (a) was identified in the InfoEx; and (b) had reported avalanche activity and/or snowpack observations $\geq 10$ days after burial. The threshold of 10 days for the dividing line of persistent and non-persistent weak layers was chosen as it is distinctly longer than one meteorological synoptic period (Hägeli and McClung, 2003). Snowpack and avalanche observations that were made $>10$ days after burial of the weak layer are referred to as 'persistent observations' or 'persistent avalanche activity'. Depending on whether persistent avalanche activity was observed, the persistent weak layers were labelled 'active' or 'inactive'. Even though inactive weak layers did not result in any reported avalanche activity, the fact that they were monitored persistently and reported to the InfoEx is a sign of their continuous importance for expected local avalanche activity and related decision-making.

This definition of persistence is different from those used in previous studies. While the classification of Jamieson (1995) is based purely on types of weak-layer crystal, Hägeli and McClung (2003) used snowfall data to directly determine the synoptic period and distinguish between avalanche activity on non-persistent and persistent weak layers. The data available in the InfoEx dataset did not permit the use of one of these more established definitions. However, the method used in this study identified all significant persistent weak layers mentioned in previous studies (e.g. Jamieson and others, 2001; Hägeli and McClung, 2003).

To examine the spatial extent of individual persistent snowpack weak layers, maps were produced that show the distribution of related persistent snowpack and avalanche

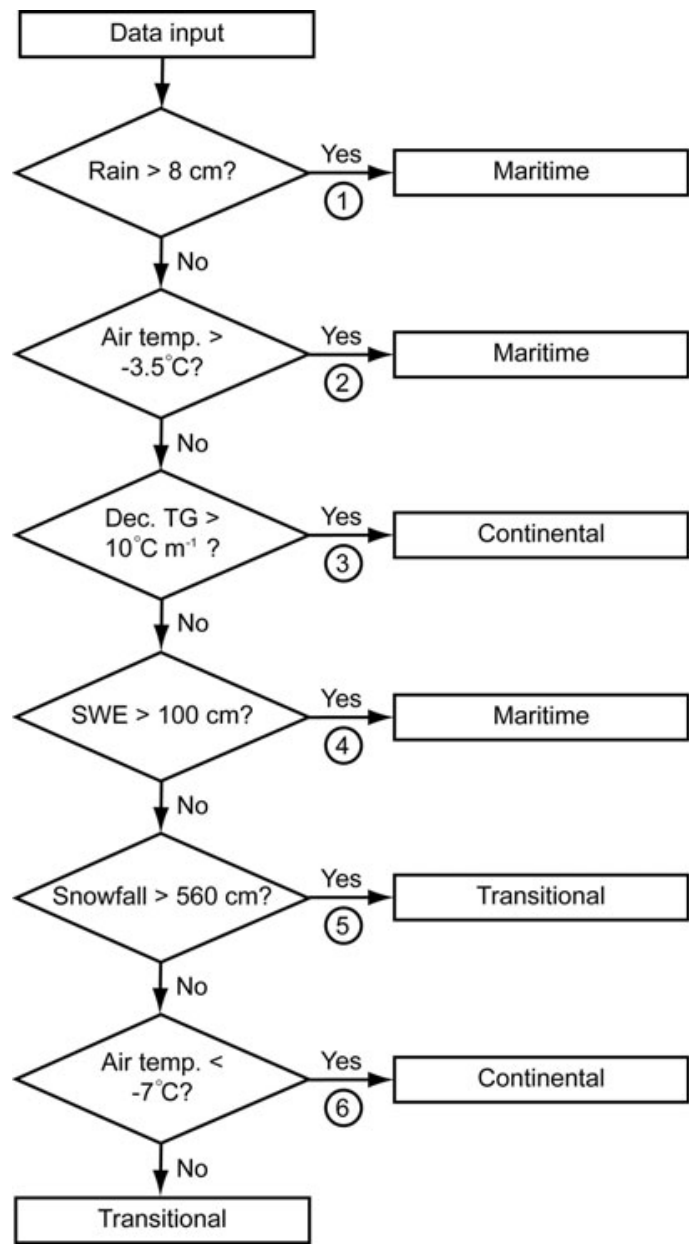

Fig. 3. Flow chart illustrating the classification procedure for the seasonal snow-climate classification (after Mock and Birkeland, 2000). SWE: snow water equivalent, TG: temperature gradient.

activity observations across the study area (see Hägeli, 2004, for examples). Although only $20 \%$ of all avalanche records in the InfoEx database contain explicit data on weak layers, this information was used to determine the dominant types of crystal in persistent weak layers. Available snowpack comments were used to supplement the characterization of the weak layers.

In accordance with the study of Hägeli and McClung (2003), persistent weak layers were grouped into three main categories: (a) layers with faceted crystals as the main weakness, including facet-crust combinations (Jamieson, 2006); (b) surface-hoar layers; and (c) pure crust layer interfaces. While recent research shows that so-called pure crust layers are usually associated with thin layers of faceted crystals (Jamieson, 2006), the data available in the InfoEx database did not allow such a detailed level of classification.

The maps of individual persistent weak layers were combined to produce seasonal contour maps (Fig. 4) that display the number of persistent weak layers across the study area grouped into the three main categories. While the contour lines are reliable in the central portion of the study area, the reliability on the periphery is more limited due to the smaller number of observation points. Similar maps were created to examine the seasonal patterns of observed avalanche activity on persistent weak layers (Fig. 5).

Even though the analysis of these maps revealed consistent seasonal patterns of frequency and combinations 


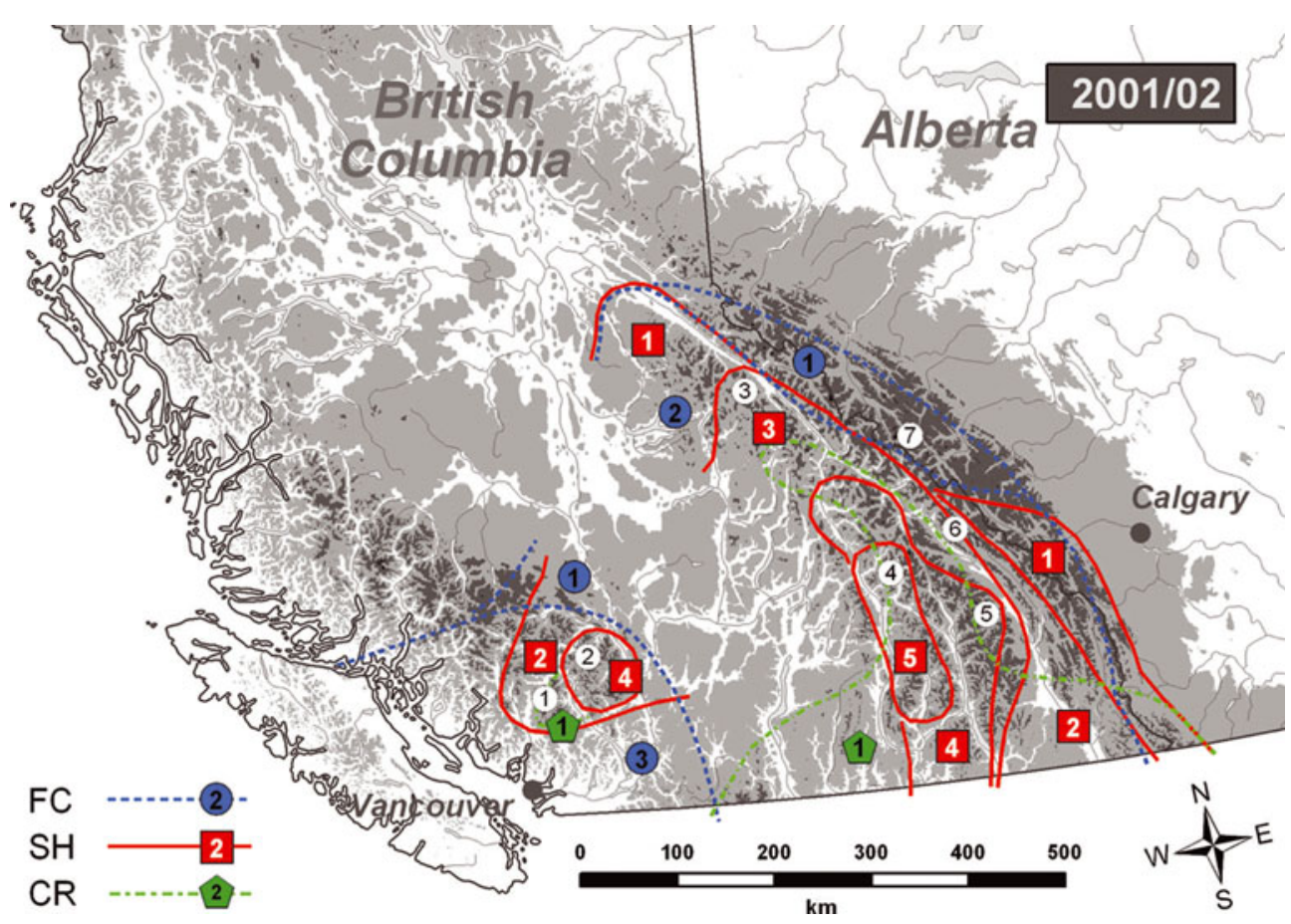

Fig. 4. Contour map showing the number of observed persistent snowpack weak layers across the study area during the winter season of 2001/ 02 (FC: layers of faceted grains; SH: surface-hoar layers; CR: pure crust layers). White numbers indicate general locations of idealized profiles.

of weak layers across the study area, the limited number of winters analyzed did not allow a delineation of homogeneous climatological regions. Instead, central point locations were chosen to represent the apparent climatological regions (Table 1; Fig. 4). Seasonal variability and spatial variations of persistent snowpack weak layers were examined in more detail by constructing idealized snow profiles (Fig. 6) for each of the representative point locations. These profiles present the observed sequences of active and inactive persistent weak layers in the different areas for each winter.

Preliminary climatological snow profiles (Fig. 6) were generated for each representative location to approximate the climatological snowpack characteristics for the regions during the entire study period. These profiles were constructed by averaging the number of observed persistent weak layers of the various types between 1996/97 and 2001/ 02. The succession of weak layers in these average profiles

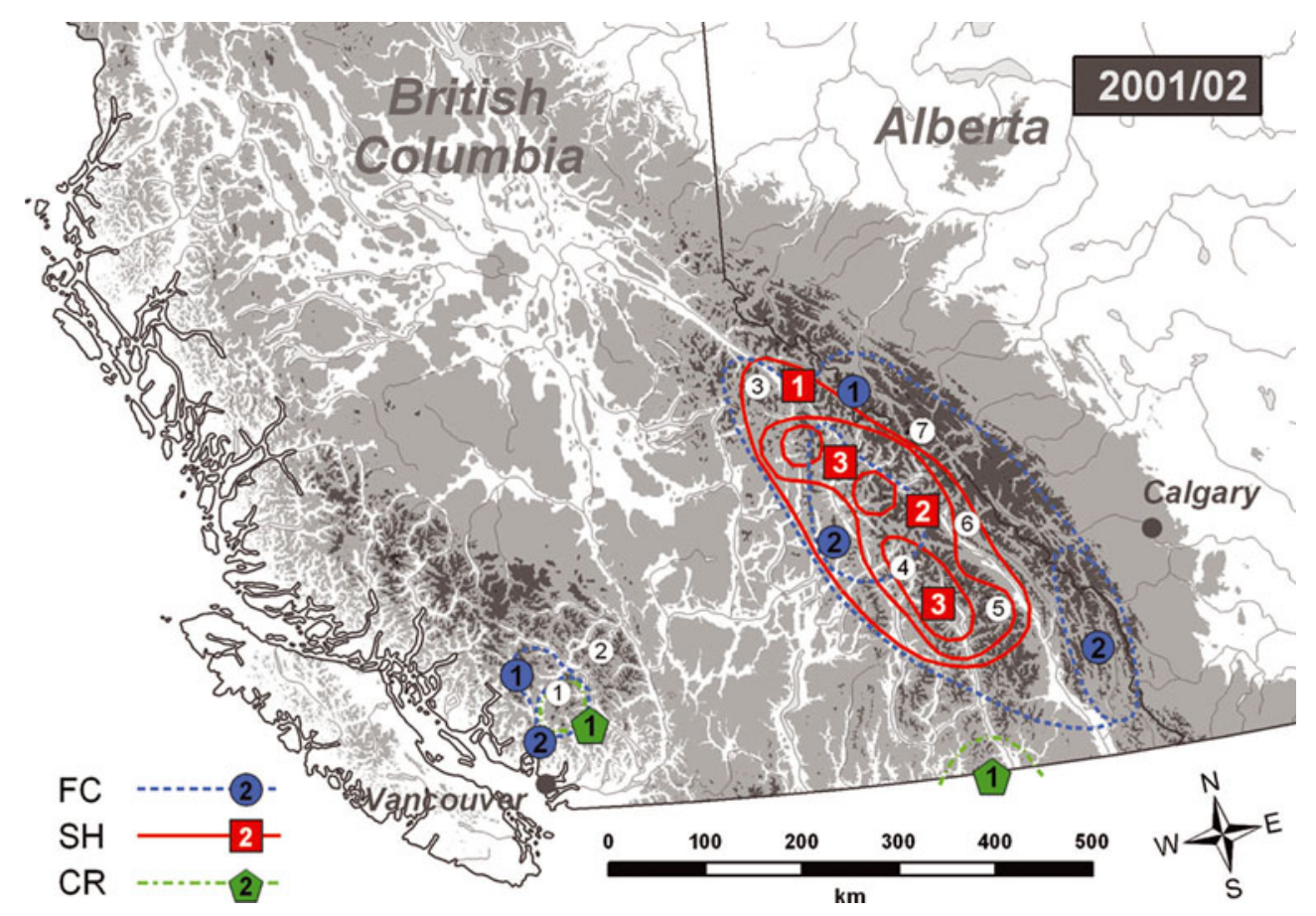

Fig. 5. Contour map showing the number of areas of persistent weak layers with observed avalanche activity during the winter season of 2001/02. Legend and labels are the same as in Figure 4. 


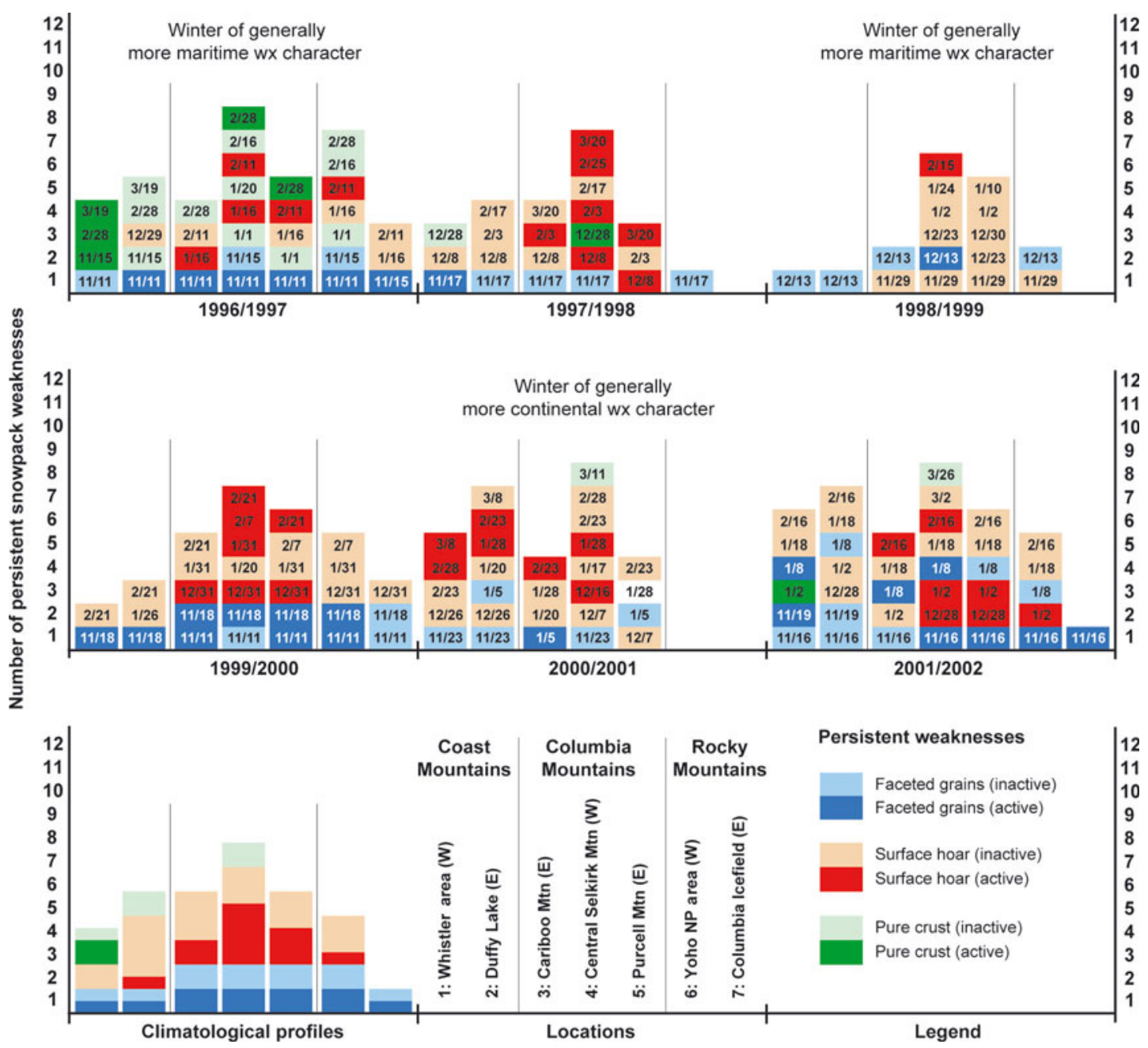

Fig. 6. Idealized snow profiles showing the frequency and sequence of active and inactive persistent weak layers in different avalanche regime areas for the seasons $1996 / 97$ to 2001/02. The labels show the burial date of the respective weakness. The bottom left panel presents average profiles for the different avalanche winter regimes.

reflects the general sequence observed during the seasons analyzed. Although a dataset of six seasons is somewhat limited, these profiles do provide reasonable first estimates of climatological avalanche-relevant snowpack characteristics in southwestern Canada.

\section{RESULTS}

The results of the two steps of analysis are presented separately. Each discussion is subdivided into three sections which examine the results with respect to spatial, temporal and climatological average patterns.

\subsection{Snow-climate analysis}

\subsubsection{Climatological patterns}

The analysis of average values of the weather records at the different weather stations suggests that Whistler, the only station in the Coast Mountains, has a maritime snow climate (Fig. 7). This classification is primarily due to an average amount of winter rain of $307 \mathrm{~mm}$ during December-March.

Table 1. Description of representative locations for different regions of similar persistent weak-layer and related avalanche characteristics

\begin{tabular}{lll}
\hline No. & Representative location & Description of region \\
\hline 1 & Whistler area & Western section of southern Coast Mountains \\
2 & Duffy Lake & Eastern section of southern Coast Mountains \\
3 & Eastern Cariboo Mountains & Northeastern section of Columbia Mountains \\
4 & Central Selkirk Mountains & Western section of central Columbia Mountains \\
5 & Eastern Purcell Mountains & Southeastern section of Columbia Mountains \\
6 & Yoho National Park area & Central Rocky Mountains west of continental divide \\
7 & Columbia Icefield & Central Rocky Mountains along and east of continental divide
\end{tabular}

Note: Locations are indicated in Figures 4-6. 


\begin{tabular}{|c|c|c|c|c|c|c|c|}
\hline \multirow{2}{*}{ Season } & \multirow{2}{*}{$\begin{array}{c}\text { Overall } \\
\text { classification }\end{array}$} & \multirow{2}{*}{$\begin{array}{l}\text { Coast Mtn } \\
\text { Whistler }\end{array}$} & \multicolumn{2}{|c|}{ North Columbia } & \multicolumn{2}{|c|}{ South Columbia } & \multirow{2}{*}{$\begin{array}{c}\text { Rocky Mtn } \\
\text { Parkers }\end{array}$} \\
\hline & & & Sun Peaks & Fidelity & Big White & Kootenay & \\
\hline Average & & 1 & 7 & 1 & 7 & 7 & 3 \\
\hline $80 / 81$ & \multirow{8}{*}{$\begin{array}{l}\text { Continental } \\
\text { Continental }\end{array}$} & 1 & - & 1 & - & - & 3 \\
\hline $81 / 82$ & & 5 & - & 4 & 3 & 1 & 3 \\
\hline $82 / 83$ & & 5 & 7 & 5 & 5 & 1 & 3 \\
\hline $83 / 84$ & & 3 & 3 & 1 & 3 & 3 & 3 \\
\hline $84 / 85$ & & 1 & 6 & 5 & 6 & 3 & 3 \\
\hline $85 / 86$ & & 1 & 7 & 1 & 7 & 7 & 3 \\
\hline $86 / 87$ & & 1 & 7 & 1 & 3 & 5 & 3 \\
\hline $87 / 88$ & & 5 & 6 & 4 & 7 & 5 & 3 \\
\hline $88 / 89$ & \multirow[t]{3}{*}{ Continental } & 5 & 6 & 5 & 6 & 5 & 3 \\
\hline $89 / 90$ & & 5 & 7 & 4 & 7 & 5 & 3 \\
\hline $90 / 91$ & & 5 & 3 & 5 & 3 & 1 & 3 \\
\hline $91 / 92^{*}$ & Maritime & 2 & 7 & 5 & 2 & 5 & 7 \\
\hline $92 / 93^{\star}$ & \multirow[t]{4}{*}{ Continental } & 7 & 6 & 3 & 6 & 3 & 3 \\
\hline $93 / 94^{*}$ & & 5 & 7 & 5 & 7 & 4 & 6 \\
\hline $94 / 95^{*}$ & & 1 & 7 & 5 & 7 & 1 & 3 \\
\hline $95 / 96^{\star}$ & & 1 & 6 & 1 & 7 & 1 & - \\
\hline $96 / 97^{* *}$ & \multirow[t]{2}{*}{ Maritime } & 5 & 1 & 4 & 7 & 1 & 3 \\
\hline $97 / 98^{* *}$ & & 1 & 3 & 5 & - & 5 & - \\
\hline $98 / 99^{* *}$ & \multirow[t]{2}{*}{ Maritime } & 1 & - & 4 & 5 & 4 & - \\
\hline $99 / 00^{* *}$ & & 5 & 7 & 5 & - & 4 & 6 \\
\hline $00 / 01^{* *}$ & \multirow[t]{2}{*}{ Continental } & 1 & - & 5 & - & 3 & - \\
\hline $01 / 02^{* *}$ & & 1 & 5 & 1 & - & - & 3 \\
\hline $\mathrm{M} / \mathrm{T} / \mathrm{C}$ & & $11 / 10 / 1$ & $1 / 9 / 8$ & $11 / 10 / 1$ & $1 / 10 / 6$ & $9 / 7 / 4$ & $0 / 1 / 17$ \\
\hline
\end{tabular}

Fig. 7. Results of snow-climate analysis: maritime (dark shading), transitional (intermediate shading), continental (light shading) and missing data (no shading). Numbers represent decision in classification flow chart (Fig. 3). First column shows the character of large-scale snowclimate deviations from average conditions across the entire study area. Asterisks indicate winters with InfoEx data; double asterisks indicate winters considered in the snowpack weakness analysis. Bottom row (M/T/C) summarizes numbers of snow-climate classifications of each type (maritime/transitional/continental).

All stations in the Columbia Mountains, except Mount Fidelity, are considered to have a transitional snow climate. Mount Fidelity is classified as maritime due to an average amount of rain of $82 \mathrm{~mm}$, which is barely above the threshold of $80 \mathrm{~mm}$. Parkers Ridge, the only station in the Rocky Mountains, is classified as having a continental snow climate.

These results are in general agreement with the traditional snow-climate classification of these mountain ranges by McClung and Schaerer (1993). The maritime influence at Mount Fidelity agrees with the reputation of the Rogers Pass region as an area with particularly large amounts of precipitation (see, e.g., CCBFC, 1995).

\subsubsection{Spatial patterns}

The year-by-year analysis reveals a west-east pattern in snow-climate classifications in the Columbia Mountains, which further confirms the more maritime classification of Rogers Pass (Fig. 7).

Sun Peaks and Big White, both stations on the far western side of the mountain range (Fig. 2), are dominated by winters with transitional and continental characteristics. Sun Peaks, the more northerly station of the two, has slightly more continental winters, while both stations experienced only one maritime winter during the entire study period. Mount Fidelity and Kootenay Pass, which are located more centrally in the Columbia Mountains, have more of a maritime influence despite their location further inland. In the case of Mount Fidelity, half the winters are classified as maritime. Kootenay Pass has 9 maritime classifications within 20 winters. These classifications are the result of large amounts of rain or accumulated SWE $>10 \mathrm{~m}$. In the present analysis, this amount is equivalent to an accumulated new snowfall of $1000 \mathrm{~cm}$ from the beginning of December to the end of March. We attribute the observed pattern to: (a) the extended effect of the rain shadow of the Coast Mountains on westerly locations in the Columbia Mountains; and (b) the additional lift experienced by air masses approaching the main crest of the range.

\subsubsection{Temporal patterns}

While the climatological analysis confirmed the existing snow-climate classifications of the main mountain ranges (McClung and Schaerer, 1993; McClung and Tweedy, 1993), the year-by-year analysis shows considerable variations in annual classifications (Fig. 7).

Whistler, for example, has only half of the winters classified as maritime. In all but one case, the maritime classification was caused by the large amount of winter rainfall. Ten winters were classified as transitional, mainly due to large amounts of snowfall, and there was only one continental winter. The snow-climate classifications of the stations in the Columbia Mountains also show similar degrees of year-to-year variability. Parkers Ridge in the Rocky Mountains has the most consistent snow-climate classification, with only continental winters except the transitional season of 1991/92.

An examination of the snow-climate classification across the entire study area shows that the classifications of individual winters often exhibit similar deviations from the average conditions (Fig. 7). For the winter seasons of 1983/ 84, 1984/85, 1992/93 and 2000/01, the majority of the weather-station locations exhibited more continental conditions (for detailed weather records, see Hägeli, 2004). Weather records show that the continental classification of $1983 / 84$ was mainly due to an exceptional cold spell in December which resulted in extremely strong December snowpack temperature gradients (Hägeli, 2004). It was also 
a dry winter with little snowfall at the Whistler, Sun Peaks and Kootenay Pass stations. Mount Fidelity, the only noncontinental station of that winter, was classified as maritime due to a considerable rain event in early January. The following winter (1984/85) also had a more continental influence than average. Weather records show that it was generally a cold (Mount Fidelity, Kootenay Pass) and dry (Whistler, Kootenay Pass, Parkers Ridge) winter. The next continental winter was 1992/93. Cold temperatures during the end of December and early January (Whistler, Big White, Sun Peaks and Parkers Ridge) and a shallow early snowpack (Whistler, Mount Fidelity, Kootenay Pass) were responsible for this classification. The most recent continental winter was 2000/01, which was one of the driest winters on record at many locations in British Columbia (Hägeli, 2004). Temperatures were just slightly above normal, but there were two substantial cold spells, one in December and one in February. In combination with a shallow early-season snowpack, the first spell resulted in a strong snowpack temperature gradient during the early season.

The more maritime-influenced winters during the observation period were 1991/92, 1996/97 and 1998/99 (for detailed weather records, see Hägeli, 2004). The winter of $1991 / 92$ was the warmest during the observation period for all stations except Kootenay Pass. It was also the driest winter for Sun Peaks and Big White (Hägeli, 2004). The maritime winter of 1996/97 had completely different characteristics. It was one of the snowiest winters at Sun Peaks, Kootenay Pass and Parkers Ridge. There were also large rain events at Sun Peaks and Kootenay Pass. The winter of 1998/99 brought the most snow to Whistler, Mount Fidelity, Big White and Kootenay Pass (Hägeli, 2004).

All other winters examined in this study exhibited conditions more comparable to the average snow-climate classifications.

In conclusion, the analysis revealed that the classification scheme of Mock and Birkeland (2000) is able to adequately capture the general meteorological character of a winter. However, the discussion of individual winters shows that there are considerable spatial and temporal variations and that the classifications can be based on completely different factors at neighbouring locations during the same winter (Fig. 7). Further, the analysis highlights that the classification scheme presented is highly sensitive to single events, such as a major rainstorm or an important cold spell, which often dictate the classification.

\subsection{Analysis of persistent weak layers}

\subsubsection{Spatial patterns}

Despite the limited reliability of the weak-layer contours, the analysis revealed reasonable weak-layer patterns across the study area. Since the snow-climate classifications of the 2001/02 season are most similar to the average conditions observed during the observation period (Fig. 7), this season is used as an example to discuss the main characteristics of the observed persistent weak-layer patterns. The interested reader is referred to Hägeli (2004) for a discussion of the other winter seasons.

For 2001/02, the number of persistent layers with faceted crystals is almost constant across the entire area, but the number of surface-hoar layers varies considerably among different regions (Fig. 4). The southern Coast Mountains can be separated into a western and an eastern section. The drier eastern part generally exhibits more persistent surface-hoar layers than the western counterpart. The Columbia Mountains show the highest number of persistent surface-hoar layers, with a maximum occurring on the western side of the central Columbia Mountains. The geographic area where the maximum number of surface-hoar weak layers is observed remains reasonably stationary during the entire study period. Maps of the different winters show that the number of surface-hoar weak layers generally drops from west to east and towards the northern and southern parts of the Columbia Mountains. The Rocky Mountains can also be divided into areas with different snowpack weakness combinations. The section west of the continental divide tends to be more similar to the eastern parts of the Columbia Mountains, with a higher number of surface-hoar layers, while the rest of the range rarely experiences persistent weak layers of this type. The analysis also suggests a possible north-south division of the Rockies. However, the division cannot be demonstrated conclusively with the data at hand.

While the presence of a snowpack weakness is a prerequisite for instability, the distribution of related avalanche activity is the result of complex interactions of weaklayer and slab properties (Hägeli and McClung, 2004). Figure 5 presents the frequency and spatial character of areas of persistent avalanche activity for the winter season of 2001/02. While persistent weak layers are generally widespread, the regions with related persistent avalanche activity are considerably smaller. However, the avalanche activity patterns observed during the different seasons generally confirm the division of the study area discussed above.

\subsubsection{Climatological patterns}

The combined analysis of seasonal weak-layer maps for the winters of 1996/97 to 2001/02 reveals consistent patterns that suggest the study area can be divided roughly into seven different regions. Each of these regions exhibits a different average number and combination of weak layers and related avalanche activity during the study period. Since the limitations of the dataset do not allow a more detailed definition, these regions can only be interpreted as preliminary climatological.

Preliminary climatological profiles at the seven representative locations (Table 1; Fig. 6) show that early-season layers of faceted crystals are generally observed in all areas. Occasional pure crust layers occur predominantly in the Coast Range and on the western side of the central Columbia Mountains. The average profiles confirm the number of surface-hoar layers as the main distinguishing factor among the different regions (Fig. 6). The central Columbia Mountains experience the highest number of active and inactive surface-hoar layers. On average, there are no significant surface-hoar layers observed on the eastern slopes of the Rocky Mountains, and the Coast Mountains experience only occasional surface-hoar layers. In addition to this variation in the west-east direction, the observations also show that the number of persistent surfacehoar layers tends to decrease towards the north and south within the Columbia Mountains.

Overall, these observations clearly indicate that the transitional Columbia Mountains have distinct weak layers and avalanche activity characteristics that go beyond a simple combination of maritime and continental influences. These results are in agreement with the preliminary study of Gruber and others (2004). 


\subsubsection{Temporal patterns}

To examine the seasonal variability of weak-layer patterns in detail, the idealized snow profiles of the different winters were compared with their respective average profile.

According to their snow-climate classifications, the winters of 1997/98, 1999/2000 and 2001/02 are most similar to the average conditions observed in the study (Fig. 7). All these seasons were classified as regular winters with no particular maritime or continental tendencies. While the weak-layer patterns observed during the winter of 1999/2000 are most similar to the climatological average (Fig. 6), the other two winters exhibit distinct peculiarities. In comparison with other winters examined in this study, the weak layer of faceted grains of 8 January 2002 stands out as an irregularity. This is in agreement with the analysis of Hägeli and McClung (2003), which showed that these layers of faceted grains normally develop after rain-on-snow events during the early months of the winter season. The season 1997/98 was characterized by the absence of an active early-season weak layer of faceted grains. These three winters (1997/98, 1999/ 2000, 2001/02) clearly show that there can be significant differences in persistent weak-layer characteristics among winters with similar average weather characteristics.

This variability is even more pronounced in the more maritime winters of $1996 / 97$ and 1998/99. The first season was dominated by the 11 November facet-crust combination, a small number of surface-hoar layers and numerous crust interfaces during the main winter months. The 1998/99 winter, on the other hand, was characterized by an average number of surface-hoar layers in the Columbia Mountains. However, the majority of surface-hoar layers remained inactive and did not result in persistent avalanche activity.

The only winter with a more continental snow-climate influence across southwestern Canada examined in this study is $2000 / 01$. This season is characterized by an average number of persistent weak layers in the Columbia Mountains. In comparison to the average conditions, however, only a small number of these persistent weak layers resulted in persistent avalanche activity. During this winter, the Coast Mountains experienced an exceptionally large number of persistent surface-hoar weak layers, while, at the same time, no distinct persistent weak layers were reported in the Rocky Mountains.

Even though the dominance of early-season faceted layers in the Rocky Mountains is in agreement with the generally weak foundation of the snowpack in this region (McClung and Schaerer, 1993), it is rather surprising that depth hoar did not emerge as a significant weakness for that region. We suspect this to be an artefact of the dataset, since it has been shown that depth hoar is only of limited importance for avalanches triggered by human activity (see fig. 4 in Schweizer and Jamieson, 2001). However, a rough analysis of avalanche-bed surface types (categories 'storm snow', 'old interface' and 'ground'; CAA, 2002) shows a considerably higher percentage of reported ground avalanches in the Rocky Mountains than in other areas (Hägeli, 2004), which can be interpreted as a potential increase in the local importance of depth-hoar avalanches. This observation clearly underlines the importance of recognizing observational biases in operational datasets.

\section{DISCUSSION}

The snow-climate classification scheme of Mock and Birkeland (2000) provided a useful tool for characterizing average winter weather conditions across the study area. The overall classification agreed with existing assessments of the snow climate of the three main mountain ranges (e.g. McClung and Schaerer, 1993; Gruber and others, 2004). The method also allowed the identification of winters that showed homogeneous deviations from the climatological average conditions across the entire study area. Within the 21 winters covered by the study, five had a more continental character while three had more maritime-influenced weather. However, the results also showed significant classification variability within the same mountain ranges and that a single weather event can completely change the local climate classification of a winter. We therefore suggest that proper snow-climate classifications should not be used below the mountain-range scale and that their derivation should include data from a number of representative weather stations.

Seasonal maps of persistent weak-layer distributions showed that the weak-layer patterns can vary considerably depending on the weather characteristics of the particular winter. Even though the number of winters with reliable data is limited, it was possible to reveal preliminary climatological patterns. The number of surface-hoar weak layers emerged as the main distinguishing variable between different areas. The fact that the highest number of persistent weak layers is found in the Columbia Mountains confirms the results of the preliminary study of weak layers by Gruber and others (2004).

The analysis of idealized snow profiles showed considerable variation in the snowpack weak-layer combinations of different winters, even among those classified similarly by the scheme of Mock and Birkeland (2000). The most dramatic example presented in this study is the difference in snowpack weak-layer combinations between the maritime seasons of 1996/97 and 1998/99. Similarly, Whistler and Mount Fidelity exhibit considerably different weak-layer characteristics, despite their comparable snow-climate classification.

All these results emphasize that there are critical limitations in the existing snow-climate classification scheme for effectively capturing important parameters that determine the avalanche activity in a region. While the weaklayer patterns generally follow existing snow-climate classifications, the analysis revealed notable additional complexities. The analysis showed considerable variability of weak-layer patterns within, but also a more gradual transition between, existing snow-climate zones. We suggest 'avalanche winter regime' as a new classification term to describe the seasonal characteristics of snowpack structures relevant for local avalanche activity. The analysis of persistent weak layers revealed three distinct regimes with respect to weak-layer combinations and related avalanche activity. Type localities of the three distinct winter regimes are Whistler, central Selkirk Mountains and Columbia Icefield (Table 2). The snowpack weakness characteristics of the other regions (Table 1) generally show intermediate properties and can be interpreted as transitions between the three base regimes.

The idealized snow profiles (Fig. 7) show that local avalanche winter regimes vary considerably from season to season, similar to observed snow-climate characteristics. While a shift of the maximum number of persistent surfacehoar layers towards the Coast Mountains was observed during the only more continental winter (2000/01), there is 
Table 2. Representative locations and description of characteristics of the three types of avalanche winter regime

\begin{tabular}{llcl}
\hline No. & Avalanche winter regime area & Number of persistent weaknesses & Dominant persistent weak layers \\
\hline 1 & Whistler area & $3-4$ & Several pure crust interfaces \\
4 & Central Selkirk Mountains & 7 & One facet-crust weak layer; several surface-hoar weak layers \\
7 & Columbia lcefield & 1 & One weak layer of faceted grains (potentially depth hoar) \\
\hline
\end{tabular}

Note: Locations are indicated in Figures 4-6.

no detectable east-to-west shift of the observed weak-layer pattern during more maritime winters. We suspect that an important reason for the apparent absence of persistent surface-hoar layers in the Rocky Mountains is the prevalence of low humidity coupled with low temperatures. Optimal surface-hoar formation occurs when warm, moist air is present over a cooling snow surface. Even winters with dominant maritime influences do not seem strong enough to provide the necessary conditions in the Rocky Mountains. Together with the consistent continental snow-climate classification at Parkers Ridge, this observation clearly highlights the climatological stability of the snow and avalanche conditions in the Rocky Mountains.

\section{CONCLUSION}

The goal of this study was to expand the traditional snowclimate classification approach by including snowpack characteristics that directly relate to local avalanche activity. Existing snow-climate classifications are primarily based on meteorological parameters that describe the average winter during the winter months. However, since the snowpack structure necessary for avalanches is created by specific sequences of weather events, the existing classification methods can only provide limited insights with respect to avalanche formation.

The present analysis of persistent weak layers revealed considerable variability within existing snow-climate classifications and therefore confirmed the limitations mentioned above. 'Avalanche winter regime' was suggested as a new classification term to describe the seasonal characteristics of snowpack structures most important for the avalanche activity in an area (Table 2). The present study revealed three distinct types of weak-layer combinations for southwestern Canada. Numerous regions within the study area exhibit intermediate snowpack weakness characteristics.

Persistent weak layers are clearly only one of the aspects that determine the characteristics of an avalanche winter regime. This study is only a first step in the direction of a process-oriented climate classification with respect to local avalanche activity. More winters with consistent avalanche activity data are needed to expand the description of the different regimes and include more relevant parameters. In addition, more high-elevation meteorological observation sites are necessary to characterize the local sequence of weather events more accurately and to conclusively explain the observed large-scale avalanche activity patterns across the entire study area. Meteorological indicators, such as the clear-night-cold-day index used in Gruber and others (2004) or the potential for facet-crust combinations of rain-on-snow events (Hägeli and McClung, 2003), might provide means to identify and describe different avalanche winter regimes.
Similar studies in other geographic regions are necessary to identify additional avalanche winter regimes and to generalize the regime types found in southwestern Canada. Of particular interest are regions in transitional snowclimate zones where the dominant processes are different from the Columbia Mountains. An example for a potential future study site is the San Juan Mountains in Colorado, USA, (LaChapelle and Armstrong, 1976), an area where near-surface faceting (Birkeland, 1998) is the dominant process for the formation of persistent weak layers.

The expansion of the existing snow-climate definitions with avalanche winter regimes will allow a more processoriented division of southwestern Canada with respect to avalanche activity. While forecast domains for public bulletins are currently largely defined on an ad hoc basis based on mountain geography and experience, the establishment of more natural forecast regions would most likely help to improve the delivery of public avalanche bulletins and facilitate the data interpretation in industrial information exchanges like the InfoEx.

A detailed description of avalanche winter regimes and their relation to the snow-climate zones might also provide the necessary detail for an in-depth examination of the influence of atmospheric oscillations, such as El NiñoSouthern Oscillation (Bonsal and others, 2001) or North Atlantic Oscillation (Keylock, 2003), on the local avalanche activity patterns. Such an analysis could be particularly useful for the prediction of future avalanche activity characteristics with respect to different climate-change scenarios. While the number of seasons covered by the InfoEx dataset is too small for an in-depth analysis of this topic, the present analysis clearly shows that changes in the winter weather patterns in southwestern Canada could potentially lead to considerable changes in the existing avalanche activity patterns.

\section{ACKNOWLEDGEMENTS}

We express our appreciation to the Canadian Avalanche Association and all the operations contributing to the InfoEx for their data collection and the opportunity to use this extraordinary database for research purposes. We thank U. Gruber, C. Donofrio and Z. Simon for their work during the InfoEx data transformation. We also thank J. Schweizer and D. Steyn for suggestions during the early stages of this research. P. Bartelt and two anonymous reviewers provided insightful comments on the manuscript. We are grateful for the financial support of Canadian Mountain Holidays, the Natural Sciences and Engineering Research Council of Canada, and the Vice President of Research of the University of British Columbia. P. Haegeli was supported by a University Graduate Fellowship of the University of British Columbia. 


\section{REFERENCES}

Armstrong, R.L. and B.R. Armstrong. 1987. Snow and avalanche climates of the western United States: a comparison of maritime, intermountain and continental conditions. IAHS Publ. 162 (Symposium at Davos 1986 - Avalanche Formation, Movement and Effects), 281-294.

Birkeland, K.W. 1998. Terminology and predominant processes associated with the formation of weak layers of near-surface faceted crystals in the mountain snowpack. Arct. Alp. Res., 30(2), 193-199.

Birkeland, K.W. 2001. Spatial patterns of snow stability throughout a small mountain range. J. Glaciol., 47(157), 176-186.

Bonsal, B.R., A. Shabbar and K. Higuchi. 2001. Impacts of low frequency variability modes on Canadian winter temperature. Int. J. Climatol., 21(1), 95-108.

Canadian Avalanche Association (CAA). 2002. Observation guidelines and recording standards for weather, snowpack, and avalanches. Revelstoke, BC, Canadian Avalanche Centre.

Canadian Commission on Building and Fire Codes (CCBFC). 1995. National building code of Canada (NBC). Ottawa, Ont., National Research Council of Canada.

Gruber, U., P. Hägeli, D.M. McClung and E. Manners. 2004. Largescale snow instability patterns in western Canada: first analysis of the CAA-InfoEx database 1991-2002. Ann. Glaciol., 38, 15-20.

Hägeli, P.T. 2004. Scale analysis of avalanche activity on persistent snowpack weaknesses with respect to large-scale backcountry avalanche forecasting. (PhD thesis, University of British Columbia.)

Hägeli, P. and D.M. McClung. 2003. Avalanche characteristics of a transitional snow climate - Columbia Mountains, British Columbia, Canada. Cold Reg. Sci. Technol., 37(3), 255-276.

Hägeli, P. and D.M. McClung. 2004. Hierarchy theory as a conceptual framework for scale issues in avalanche forecast modeling. Ann. Glaciol., 38, 209-214.

Jamieson, J.B. 1995. Avalanche prediction for persistent snow slabs. (PhD thesis, University of Calgary.)

Jamieson, J.B. 2006. Formation of refrozen snowpack layers and their role in slab avalanche release. Rev. Geophys., 44(2), RG2001. (10.1029/2005RG000176.)

Jamieson, J.B., T. Geldsetzer and C. Stethem. 2001. Forecasting for deep slab avalanches. Cold Reg. Sci. Technol., 33(2-3), 275-290.
Keylock, C.J. 2003. The North Atlantic Oscillation and snow avalanching in Iceland. Geophys. Res. Lett., 30(5), 1254. (10.1029/2002GL016272.)

Köppen, W.P. 1918. Klassification der Klimate nach Temperatur, Niederschlag und Jahreslauf. Petermanns Geogr. Mitt., 64, 193203, 243-248.

LaChapelle, E.R. 1966. Avalanche forecasting - a modern synthesis. IASH Publ. 69 (Symposium at Davos 1965 - Scientific Aspects of Snow and lce Avalanches), 350-356.

LaChapelle, E.R. and R.L. Armstrong. 1976. Nature and causes of avalanches in the San Juan Mountains. In Armstrong, R.L. and J.D. Ives, eds. Avalanche release and snow characteristics - San Juan Mountains, Colorado. Boulder, CO, University of Colorado.

Laternser, M. and M. Schneebeli. 2002. Temporal trend and spatial distribution of avalanche activity during the last 50 years in Switzerland. Natur. Hazards, 27, 201-230.

McClung, D.M. 2002. The elements of applied avalanche forecasting - Part II: the physical issues and the rules of applied avalanche forecasting. Natur. Hazards, 26(2), 131-146.

McClung, D.M. and P.A. Schaerer. 1993. The avalanche handbook. Seattle, WA, The Mountaineers.

McClung, D.M. and J. Tweedy. 1993. Characteristics of avalanching: Kootenay Pass, British Columbia, Canada. J. Glaciol., 39(132), 316-322.

Mingo, L. and D.M. McClung. 1998. Crocus test results for snowpack modeling in two snow climates with respect to avalanche forecasting. Ann. Glaciol., 26, 347-356.

Mock, C.J. and K.W. Birkeland. 2000. Snow avalanche climatology of the western United States mountain ranges. Bull. Am. Meteorol. Soc., 81(10), 2367-2392.

Roch, A. 1949. Report on snow avalanche conditions in the U.S.A. western ski resorts from the 26th January to the 24th of April, 1949. Eidg. Inst. Schnee- Lawinenforsch. Interner Ber. 174.

Röger, C. 2001. Verification of numerical weather prediction and avalanche forecasting. (MSc thesis, University of British Columbia.)

Schweizer, J. and J.B. Jamieson. 2001. Snow cover properties for skier triggering of avalanches. Cold Reg. Sci. Technol., 33(2-3), 207-221.

Schweizer, J., J.B. Jamieson and M. Schneebeli. 2003. Snow avalanche formation. Rev. Geophys., 41(4), 1016. (10.1029/ 2002RG000123.) 